\title{
Climate science is monopolized, so is conservation science
}

\author{
Minh-Hoang Nguyen \\ Ritsumeikan Asia Pacific University \\ Beppu, Oita 874-8577, Japan \\ November 12, 2021

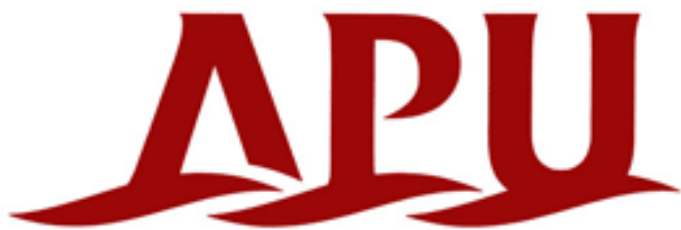 \\ Ritsumeikan Asia Pacific University
}

Dr Quan-Hoang Vuong, Director of the Centre for Interdisciplinary Social Research, Phenikaa University, gives opinions about Western monopoly within climate science on Economy, Land and Climate Insight [1]. He advocates that the dominance of Western countries in climate science is leading to the 'eco-deficit culture' and slow interventions of private sectors among the Global South countries [2-4].

I agree with his perspective and think that the monopoly is not limited to only climate science but also conservation science.

Knowledge from indigenous scholars and communities plays a crucial role in managing global ecosystems and biodiversity conservation. As such, it is stipulated as Target 18 of the Aichi Biodiversity Targets:

"By 2020, the traditional knowledge, innovations and practices of indigenous and local communities relevant for the conservation and sustainable use of biodiversity, and their customary use of biological resources, are respected, subject to national legislation and relevant international obligations, and fully integrated and reflected in the implementation of the Convention with the full and effective participation of indigenous and local communities, at all relevant levels."

Yet, scientific studies related to Target 18 constitutes only a modest proportion of publications relevant to the Aichi Targets (6.1\%). In comparison, a majority of research $(61.2 \%)$ is biased towards Target 11 (increasing the protected and conserved areas) [5]. The overemphasis on Target 11 demonstrates a very Western approach, which is resource-intensive and state intervention demanding. Even if Target 11 is the most 
important and feasible Target that can be achieved, it cannot be accomplished by simply buying more land. Expansion of protected areas requires the involvement of many stakeholders, including the local governments, organizations, researchers, and residents [6].

The publication statistics in biodiversity conservation research also present the dominance of Western countries [7]. The global bibliometric analysis of biodiversity research during $1900-2009$, in which biodiversity conservation is a major topic, shows that most authors are from North America and Europe. Only three non-Western institutions belong to the list of 30 most productive institutions. China and India are the only two non-Western countries ranked among top ten most productive countries and territories.

Climate change and biodiversity loss are reaching the point of no return. They are global problems, so the Global North and Global South must unite before too late [8]. Voices of non-Western climate and conservation scholars should be valued adequately [1], and cooperation initiatives, like for a Place, should be promoted and implemented widely [9].

\section{References}

1. Vuong QH. (2021). Western monopoly of climate science is creating an eco-deficit culture. Economy, Land \& Climate Insight. Retrieved from: https://elcinsight.org/western-monopoly-of-climate-science-is-creating-an-eco-deficitculture/

2. Vuong QH, La VP, Ho MT, Trang VT, Ho MT. (2020). Identifying the moral-practical gaps in corporate social responsibility missions of Vietnamese firms: an eventbased analysis of sustainability feasibility. Corporate Social Responsibility and Environmental Management, 28(1), 30-41.

3. Vuong QH. (2020). From children's literature to sustainability science, and young scientists for a more sustainable Earth. Journal of Sustainability Education, 24.

4. Vuong QH. (2021). The semiconducting principle of monetary and environmental values exchange. Economics and Business Letters, 10(3), 284-290.

5. Green, E. J., Buchanan, G. M., Butchart, S. H., Chandler, G. M., Burgess, N. D., Hill, S. L., \& Gregory, R. D. (2019). Relating characteristics of global biodiversity targets to reported progress. Conservation Biology, 33(6), 1360-1369.

6. Buckley, R. (2012). Tourism, conservation and the Aichi targets. Parks, 18(2), 1219.

7. Liu X, Zhang L, Hong S. (2011). Global biodiversity research during 1900-2009: a bibliometric analysis. Biodiversity and conservation, 20(4), 807-826.

8. Nguyen MH, Vuong QH. (2020). Evaluation of the Aichi Biodiversity Targets: The international collaboration trilemma in interdisciplinary research. OSF Preprints. Retrieved from: https://osf.io/84j76/ 
9. Borrelle SB, et al. (2020). What does it mean to be for a Place? Pacific Conservation Biology, Online Early. 